Review

\title{
Animal Models of Tick-Borne Hemorrhagic Fever Viruses
}

\section{Marko Zivcec $^{1,2}$, David Safronetz ${ }^{2}$ and Heinz Feldmann ${ }^{1,2, *}$}

1 Department of Medical Microbiology and Infectious Diseases, University of Manitoba, Winnipeg R3E 0J9, Canada; E-Mails: zivcecm@ niaid.nih.gov

2 Laboratory of Virology Division of Intramural Research, National Institute Allergy and Infectious Disease, National Institutes of Health, Rocky Mountain Laboratories, Hamilton 59840, Montana, USA; E-Mail: safronetzd@niaid.nih.gov

* Author to whom correspondence should be addressed; E-Mail: feldmannh@ niaid.nih.gov; Tel.: +1-406-375-7410; Fax: +1-406-375-7416.

Received: 7 March 2013; in revised form: 3 May 2013 / Accepted: 9 May 2013 /

Published: 28 May 2013

\begin{abstract}
Tick-borne hemorrhagic fever viruses (TBHFV) are detected throughout the African and Eurasian continents and are an emerging or re-emerging threat to many nations. Due to the largely sporadic incidences of these severe diseases, information on human cases and research activities in general have been limited. In the past decade, however, novel TBHFVs have emerged and areas of endemicity have expanded. Therefore, the development of countermeasures is of utmost importance in combating TBHFV as elimination of vectors and interrupting enzootic cycles is all but impossible and ecologically questionable. As in vivo models are the only way to test efficacy and safety of countermeasures, understanding of the available animal models and the development and refinement of animal models is critical in negating the detrimental impact of TBHFVs on public and animal health.
\end{abstract}

Keywords: Omsk hemorrhagic fever virus; Kyasanur forest disease virus; severe fever with thrombocytopenia syndrome virus; Crimean-Congo Hemorrhagic fever virus; animal models 


\section{Introduction}

Tick-borne pathogens are ubiquitously present throughout the world and are significant global health and agricultural concerns. Ticks serve as vectors and/or reservoirs for bacterial and viral pathogens with enzootic life cycles. The enzootic life cycle of many of these pathogens is often understudied, however with increases in agricultural activity and expansion into previously unutilized lands contact between humans, domesticated and wild animals, and ticks is increasing. Increased contact has resulted in recent emergence of several important zoonotic pathogens and in particular novel viruses. Tick-borne viruses (TBVs) account for a significant portion of tick-borne disease burden especially in the Eurasian and African continents.

Many tick species carry TBVs and the clinical disease caused by these viruses vary broadly. Humans are typically incidental dead-end hosts for TBVs and outbreaks caused by TBVs are usually sporadic, however sustained outbreaks of disease have also been reported [1]. TBVs of clinical concern can be separated into two broad categories: those causing neurologic disease and those causing visceral disease often associated with hemorrhagic manifestations. Clinically relevant TBVs causing neurologic disease including tick-borne encephalitis virus (TBEV) while clinically important visceral TBVs include Crimean-Congo hemorrhagic fever virus (CCHFV), Kyasanur forest disease virus (KFDV) and the related Alkhumra or Alkhurma hemorrhagic fever virus (AHFV), Omsk hemorrhagic fever virus (OHFV) and severe fever with thrombocytopenia syndrome virus (SFTSV). Neurologic TBVs, predominantly TBEV, have higher incidence rates and are extensively reviewed elsewhere [2-7]. Visceral TBVs or tickborne hemorrhagic fever viruses (TBHFVs) have a lower but significant impact on human health and are often understudied. Despite the classification of neurologic versus visceral disease causing TBV it is important to note that TBEV has been reported to cause hemorrhagic manifestation in a limited number of cases [8] and visceral TBVs have been reported to occasionally cause neurologic manifestations [9-12], however the distinction is based around the typical disease presentation in human patients. Due to the sporadic incidence of these severe diseases research, and in many cases clinical descriptions, have been limited. Significant efforts have been made to develop animal models to characterize disease progression, determine correlates of protection and to screen therapeutics and/or vaccines. This review will focus on animal models of TBHVs and to compare disease manifestations to human disease.

\section{Omsk Hemorrhagic Fever Virus}

\subsection{Epidemiology}

During the 1940s, physicians in the Omsk region of Russia noted unusual cases of febrile illness accompanied by hemorrhagic manifestations. Reports of disease were limited to a restricted geographic region and were associated with muskrat hunting and/or processing [13]. The etiologic agent of the disease, named Omsk Hemorrhagic Fever (OHF), was a flavivirus named Omsk hemorrhagic fever virus (OHFV) [9]. Ticks were suspected as vectors of OHFV, which was found to be transmitted to humans by direct contact with infected muskrats or through bite by Dermacentor reticulatus or D. marginatus. Those ticks are reputably the main vectors of OHFV, and exhibit transovarial and transstadial transmission of OHFV, however gamasid mites and Ixodes persulcatus are potentially also involved in OHFV's sylvatic enzootic cycle [9]. 
Figure 1. (a) Distribution of laboratory confirmed cases of tick-borne hemorrhagic fever (b) Distribution of tick species suspected or demonstrated to be vectors of tick-borne hemorrhagic fever viruses. OHFV is transmitted primarily by Dermacentor reticulatus and D. marginatus; KFDV has been shown to be transmitted by Haemaphysalis (H. spinigera, H. turturis, H. papuana kinneari, H. minuta, H. cuspidata, H. bispinosa, H. kyasanurensis, H. wellingtoni, and H. aculeate), and Ixodes (I. petauristae and I. ceylonensis) genus ticks; SFTSV is suspected to be transmitted by Haemaphysalis longicornis and CCHFV is transmitted by Hyalomma spp ticks. OHFV = Omsk hemorrhagic fever virus, KFDV = Kyasanur forest disease virus, SFTSV = Severe fever with thrombocytopenia syndrome virus, $\mathrm{CCHFV}=$ Crimean-Congo hemorrhagic fever virus .

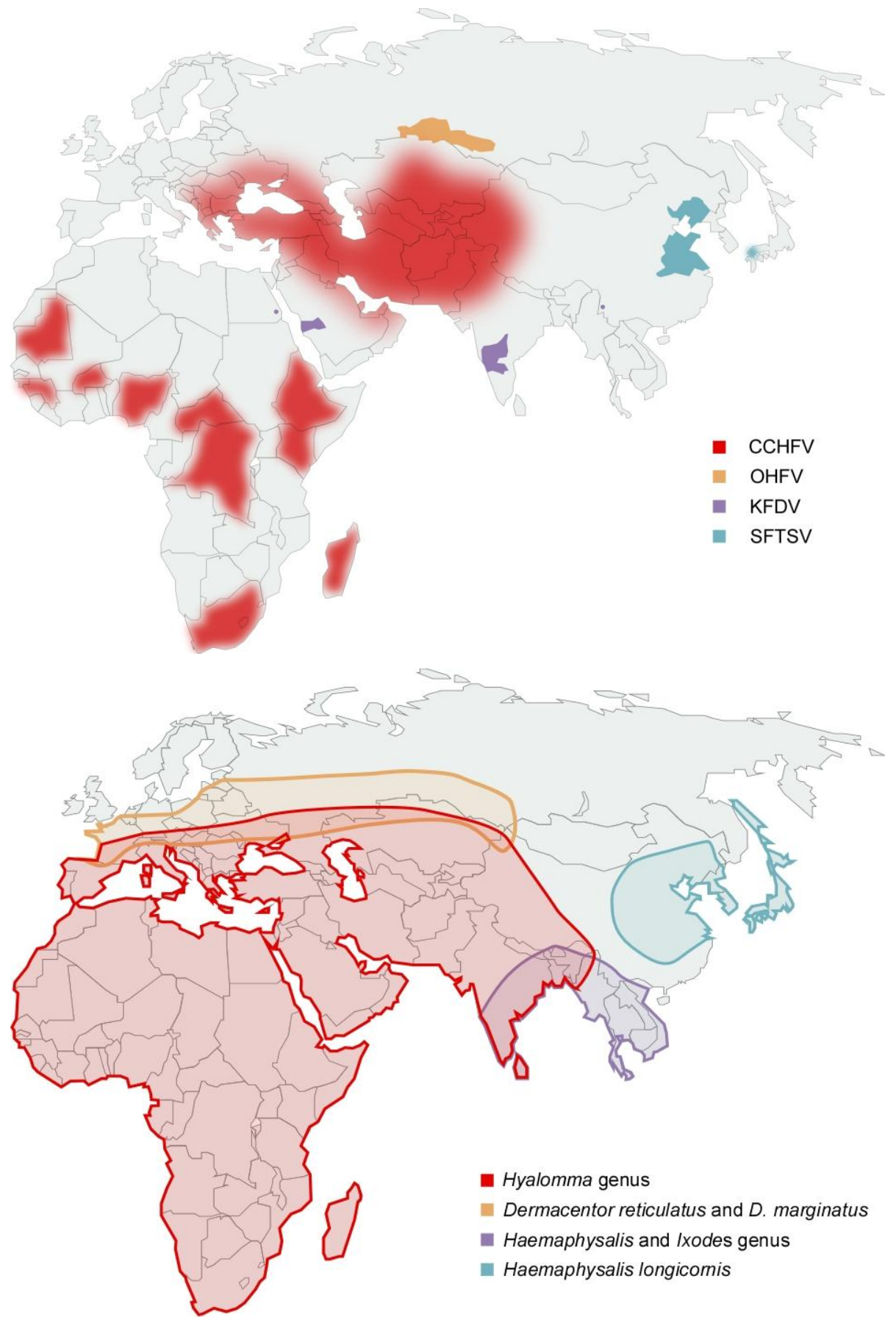


OHF has been reported in the Russian regions of Kurgan, Tjumen, Omsk and Novosibirsk; however the vectors of disease have a more broad distribution range (Figure 1) [14]. In the first decade following discovery, dozens of OHF patients were reported annually, however incidence of OHF cases has decreased 3- to 5-fold and is thought to be associated with a decrease in muskrat populations and hunting $[9,13]$. OHF has two seasonal peaks, and corresponds to increases in tick activity and the muskrat hunting season during which the majority of cases are reported [9]. OHF occurs predominantly in young adults (muskrat hunters and spouses involved with muskrat pelt processing) and children under 15 years of age (usually family members of muskrat hunters involved in muskrat pelt processing) [9].

\subsection{Clinical Presentation}

Due to the geographically limited nature of the outbreaks clinical data on OHF is limited (Table 1) [9]. However, from the available clinical data OHF begins with an incubation period, which typically lasts between 3-7 days post infection (p.i.). Following the incubation period patients develop a high fever (39-40 ${ }^{\circ} \mathrm{C}$ ), cephalalgia, cough and myalgia, often accompanied by dehydration, gastrointestinal (GI) symptoms, facial hyperemia, epistaxis, gingival and vaginal hemorrhage, hemorrhagic rash, thrombocytopenia, neutrophilia and hepatomegaly, for approximately 1-2 weeks. OHF is often biphasic and between $30-50 \%$ of patients develop a second phase of disease 1-2 weeks after primary phase resolution $[9,15]$. The second disease phase manifests with similar symptoms and duration as the first disease phase; however, development of neurological symptoms is more common. The case fatality rates vary by outbreak but are between $0.4 \%-2.5 \%[9,15]$.

Table 1. Comparison of disease signs between humans and mice following Omsk hemorrhagic fever virus infection.

\begin{tabular}{|c|c|c|}
\hline Species & Human & Mouse \\
\hline Incubation period & 3-7 days (average) & 5-8 days \\
\hline Disease duration & $8-14$ days (up to 5 weeks in biphasic patients) & 9-13 days \\
\hline Biphasic & Yes & No \\
\hline Disease signs & $\begin{array}{l}\text { Fever, cephalalgia, cough, myalgia, dehydration, } \\
\text { gastrointestinal symptoms, facial hyperemia, epistaxis, } \\
\text { gingival and vaginal hemorrhage, hemorrhagic rash, } \\
\text { hepatomegaly }\end{array}$ & $\begin{array}{l}\text { Weight loss, piloerection, } \\
\text { lethargy, hunched posture, } \\
\text { conjunctival suffusion, } \\
\text { neurological signs }\end{array}$ \\
\hline $\begin{array}{l}\text { Hematologic } \\
\text { changes }\end{array}$ & $\begin{array}{l}\text { Thrombocytopenia, leukopenia, neutrophilia, } \\
\text { monocytosis }\end{array}$ & Leukopenia, neutrophilia \\
\hline Pathologic changes & Respiratory tract, uterus, liver, GI tract & $\begin{array}{l}\text { Brain, thymus, spleen, } \\
\text { urinary tract, GI tract }\end{array}$ \\
\hline Case fatality & $0.4-2.5 \%$ & $100 \%$ \\
\hline
\end{tabular}

\subsection{Animal Models of Omsk Hemorrhagic Fever}

Following OHFV inoculation several animal species develop asymptomatic viral infection including hamsters, Norway rats, African green monkeys (AGM) and bonnet macaques $[9,16]$. To date only muskrats and mice have been reported to develop severe disease, therefore mouse models have been the primary model used in OHF studies [9,13,15-18]. 
$\mathrm{BALB} / \mathrm{c}$ and $\mathrm{C57BL} / 6$ mice are susceptible to disease following inoculation of OHFV by the intraperitoneal (i.p.) and subcutaneous (s.c.) routes. The incubation period of OHF-like disease in mice is 5-8 days p.i. following either route of infection. At disease onset, infected mice display rapid weight loss, ruffled fur, general malaise, hunched posture and conjunctival suffusion with crusting. In addition, mice develop splenomegaly, splenic hyperplasia, splenic necrosis, necrosis and apoptosis in the cerebellum accompanied by infiltration of mononuclear cells, necrosis and inflammation of the thymus, and hemorrhagic manifestations within brain, liver, urinary/reproductive and GI tract. Infected mice also develop transient leukocytopenia and neutrophilia and increases in total bilirubin, blood urea and globulin levels [17-19]. Infectious OHFV is detectable in brain, lung, liver, kidney and spleen of BALB/c mice and OHFV antigen is readily detected in the small intestine [18,19]. Disease signs are accompanied by increases in pro-inflammatory cytokines and chemokines, and splenocyte populations $[17,18]$. OHFV infection is uniformly lethal in the mouse model with an average time of 9 days p.i. to lethal disease [15]. This mouse model therefore mimics several aspects of severe human OHF (Table 1).

Neither AGM nor bonnet macaques infected with high dose of OHFV develop disease signs. Bonnet macaques do not display viremia or any pathologic manifestations while AGM support OHFV replication and may transiently display a hemolytic syndrome, accompanied with leukopenia, thrombocytopenic purpura and increases in serum aspartate aminotransferase (AST) and alanine aminotransferase (ALT) without other disease signs[16,20]. Therefore, the AGM model of OHF effectively mimics the mild to moderate disease symptoms of human OHF.

\subsection{Omsk Hemorrhagic Fever Virus Summary}

OHF is a clinically important, but rare disease, affecting a select population within a geographically restricted area. Susceptible mice develop a rapid, inflammatory syndrome, which shares some similarity to the most severe cases of human OHF. Murine models will therefore be useful for evaluating the efficacy of OHF countermeasures such as vaccines and antivirals; however due to the differences between murine and human immune systems the predictive power of this model to define disease progression and correlates of protection may be limited. Therefore, further research is needed to characterize other animal models, especially AGM, which faithfully replicate the typical human disease progression.

\section{Kyasanur Forest Disease Virus}

\subsection{Epidemiology}

Beginning in 1950s, cases of a novel febrile illness were reported in humans in Shimoga district of the Karnataka (formerly Mysore) state, India [21]. Concurrent to human cases were reports of increased incidence of finding deceased and/or moribund non-human primates (NHPs) in the surrounding forest [21,22]. The source of both human and NHP disease, named Kyasanur forest disease (KFD), was found to be a flavivirus named Kyasanur forest disease virus (KFDV) [21-23]. Ticks were implicated as vectors of KFDV due to association of reported cases with seasonal tick activity. Following extensive studies KFDV was isolated from ticks belonging to the Haemaphysalis (H. spinigera, H. turturis, H. papuana kinneari, H. minuta, H. cuspidata, H. bispinosa, $H$. kyasanurensis, H. wellingtoni, and H. aculeate) Rhipicephalus (R. haemaphysaloides), Hyalomma 
(H. marginatum issaci), Ornithodoros (O. crosi), Ixodes (I. petauristae and I. ceylonensis), Argas (A. persicus), and Dermacentor (D. auratus) genus and experimental transmission of KFDV was demonstrated by members of the Haemaphysalis and Ixodes genus of ticks [24-34].

Despite the distribution of tick vectors, KFD cases are geographically restricted to Karnataka state and following its discovery annual epidemics, comprising of hundreds of cases, have been documented (Figure 1) [10,14]. The majority of cases are reported during the first 5 months of the year, which is concurrent with greatest tick and human outdoor activity [35]. In 1989 KFDV was isolated from a single febrile patient in China however further analysis suggested that this isolate may have been a lab contaminant as it is nearly identical to the 1957 Indian reference strain P-9605 despite being isolated at a much later date in a geographically distinct area [36, 37]; in the 1990s the "KFDV-like" virus AHFV emerged in Saudi Arabia and has been subsequently reported in Egypt (Figure 1a) [38-40]. Due to low numbers of case reports (<200 reported) little information about AHFV is available. Unlike KFDV, both mosquitoes and ticks are suspected as vectors due to a lack of history of tick bite in several patients $[38,41,42]$. Genetic analyses reveal that AHFV may have diverged from KFDV approximately 700 years ago, and is still not considered a virus that is distinct from KFDV by the International Committee on Taxonomy of Viruses [43,44].

\subsection{Clinical Presentation}

KFD begins with an incubation period estimated to be between 3 and 8 days followed by sudden onset of fever, cephalalgia, diarrhea and severe myalgia (Table 2). KFD lasts approximately two weeks and can include cough, hepatomegaly, splenomegaly, epistaxis, oral and intestinal hemorrhage, and meningoencephalitis. Elevated liver enzymes, thrombocytopenia, leukopenia and anemia are also seen in patients. KFD is often biphasic with apparent convalescence often followed by a second febrile period, which is associated with meningoencephalitis [10,23]. Case fatality rates of $2-10 \%$ have been reported for KFD.

Table 2. Comparison of disease signs between humans, mice and bonnet macaques following Kyasanur forest disease virus infection.

\begin{tabular}{|c|c|c|c|}
\hline Species & Human & Bonnet Macaque & Mouse \\
\hline Incubation period & 3-8 days & 3 days & $3-5$ days \\
\hline Disease duration & $8-12$ days & 3-8 days & $6-8$ days \\
\hline Biphasic & Yes & No & No \\
\hline Disease signs & $\begin{array}{l}\text { Fever, cephalalgia, myalgia, diarrhea, } \\
\text { cough, hepatomegaly, splenomegaly, } \\
\text { epistaxis, bradycardia, oral and intestinal } \\
\text { hemorrhage, meningoencephalitis }\end{array}$ & $\begin{array}{l}\text { Fever, diarrhea, } \\
\text { bradycardia, hypotension }\end{array}$ & $\begin{array}{l}\text { Paralysis, } \\
\text { weight loss }\end{array}$ \\
\hline $\begin{array}{l}\text { Hematologic } \\
\text { changes }\end{array}$ & $\begin{array}{l}\text { Leukopenia, thrombocytopenia, } \\
\text { neutropenia, eosinopenia, elevated liver } \\
\text { enzymes }\end{array}$ & $\begin{array}{l}\text { thrombocytopenia, } \\
\text { leukopenia, elevated liver } \\
\text { enzymes }\end{array}$ & Not reported \\
\hline Pathologic changes & Kidney, liver, lung & $\begin{array}{l}\text { Kidney, liver, lung, spleen } \\
\text { and lymph nodes }\end{array}$ & Brain, lungs \\
\hline Case fatality & $2-10 \%$ & $100 \%$ & $\geq 97 \%$ \\
\hline
\end{tabular}


Clinical presentations of AHF are reported as hemorrhagic manifestations accompanied by liver dysfunction with a case fatality of up to $25 \%$ [38,45]. AHF, therefore, mimics severe KFD; however, this observation may be due to lack of reports of mild AHF cases.

\subsection{Animal Models of Kyasanur Forest Disease}

To date no animal studies have been conducted with AHFV, however based on limited serological data sheep, goats and camels are involved in the transmission cycle of AHFV [42,45].

Several rat and mouse species, gerbil, porcupines, shrews, squirrels, cattle and NHPs (bonnet macaques) have been experimentally infected with KFDV [16,22,46-54]. Of the species tested, severe disease was seen in rodents, squirrels and bonnet macaque with pathological investigations carried out only in mice and NHPs.

\subsubsection{Rodent Models of Kyasanur Forest Disease}

KFDV was first isolated by intracranial (i.c.) inoculation of serum or tissue homogenates from deceased NHPs into newborn (2-3 day old) mice [21]. Further experiments revealed that both young (3-4 week old) and adult ( $\geq 5$ week old) mice infected by the s.c., i.p. and intranasal (i.n.) route developed a rapid and lethal disease [55-57]. The disease course is dependent on both age of inoculated mice and route of infection with time to terminal disease between 5 to 11 days p.i. [57]. Mice develop moderate viremia and significant organ viral loads, especially in the brain [57]. Pathological changes following infection are limited to encephalitis and brain necrosis accompanied by interstitial pneumonitis and hemorrhage in the lungs[57]. Approximately 2-3\% of mice survive KFDV challenge and exhibit resistance to subsequent KFDV back challenge [58]. These mice exhibit persistent neurological signs and KFDV can be isolated from these mice up to eight months p.i. [58]. Due to a lack of liver and spleen pathology, presence of significant brain pathology and a rapid, lethal disease course, the mouse model may not be a predictive model of human disease (Table 2); however, it has been utilized to evaluate the protective efficacy of KFDV vaccines [59, 60].

\subsubsection{Non-human Primate Models of Kyasanur Forest Disease}

NHPs, specifically bonnet macaques (Macaca radiata), are susceptible to lethal KFD; however, the case fatality and disease burden among naturally infected bonnet macaques is unknown. KFDV infected moribund or recently deceased bonnet macaques collected in Kyasanur forest displayed liver and kidney pathology, sometimes accompanied by evidence of encephalitis [22].

Experimentally infected bonnet macaques develop diarrhea, bradycardia, hypotension, thrombocytopenia, leukopenia, anemia and elevated liver enzymes similar to humans [16, 54]. During the disease course bonnet macaques develop systemic viral distribution and shedding from pharyngeal surfaces and sometimes in urine [16]. Bonnet macaques are reported to develop either an encephalitic disease or a visceral disease following KFDV infection. The initial study detected lymphoid hyperplasia, non-specific necrosis within liver and kidney, and disseminated non-supportive encephalomyelitis [54]. Another study determined that following KFDV infection bonnet macaques manifest changes in fatty deposition in the liver, depletion of lymphocytes sometimes accompanied by 
necrosis in the lymphoid organs, and loss of architecture in the GI tract without neurologic involvement [16]. Taken together these data indicate that $M$. radiata develop a disease that mimics severe human disease suggesting that this model may be predictive of human KFD (Table 2).

\subsection{Kyasanur Forest Disease Summary}

KFD is a serious human illness with a limited geographic distribution. It has yearly incidence, which corresponds to peak activity of its tick host. Unlike many TBVs, KFDV has both rodent and NHP models. Although mice do not recapitulate human disease they are effective as screening models for evaluating vaccines and antivirals, while bonnet macaques more accurately recapitulate human disease.

\section{Severe Fever with Thrombocytopenia Syndrome Virus}

\subsection{Epidemiology}

In 2007, in the Huaiyangshan mountain range in China, patients with an unknown syndrome were reported. The disease was named severe fever with thrombocytopenia syndrome (SFTS) and was found to be a caused by a Phlebovirus of the Bunyaviridae family, named severe fever with thrombocytopenia syndrome virus (SFTSV) [61-63]. Transmission of SFTSV has not been established experimentally however SFTSV was isolated from pools of and SFTS cases are reported within the geographic distribution of Haemaphysalis longicornis implicating this tick species as a viral vector (Figure 1) [14,61,62].

As of early 2013, SFTS cases have been identified in Henan, Hubei, Shandong, Anhui, Zhejiang, Jiangsu, and Liaoning provinces of China and in South-West Japan (Figure 1a) [61-65]. Hundreds of SFTS cases are reported annually and the disease is reported predominantly between the months of May and July, which corresponds to the greatest tick and farming activity [61,62]. In addition to the suspected tick vector, human-to-human transmission due to blood contact has been documented in SFTS cases [66-68].

\subsection{Clinical Presentation}

The incubation period of SFTS following tick bite or unprotected contact with the blood of a viremic patient is unknown but secondary cases develop symptoms within 3 weeks of contact with a viremic SFTS patient (Table 3) [66-68]. SFTS begins with a non-specific prodrome including fever, cephalalgia, myalgia, arthralgia, dizziness and malaise, which persists for 3-7 days [12,68-70]. Following the prodrome patients often develop mucosal hemorrhage, hemorrhagic rash, thrombocytopenia, elevated liver enzymes, multi-organ failure, disseminated intravascular coagulopathy (DIC), and central nervous system symptoms such as confusion. The case fatality rate was initially much higher, but currently is $12-15 \%[12,61,62,68-70]$. Symptom severity is correlated to immune suppression and viremia level with fatal cases often undergoing immune-suppressive therapy and exhibiting sustained high viremia $[12,62,70]$. 


\subsection{Rodent Models of Severe Fever with Thrombocytopenia Syndrome}

SFTSV infection and disease progression has only been described in rodent models, however serological analysis implicates a role of cows, goats, sheep, dogs, pigs, chickens and hedgehogs in the SFTSV transmission cycle [71,72].

Adult BALB/c mice, Wistar rats, Kunming (KM) mice and both adult and newborn Syrian hamsters are susceptible to, but do not develop disease following, SFTSV inoculation by the i.p. or i.c. route [73]. However, newborn mice and rats are susceptible to disease following SFTSV inoculation [73].

Following i.c. inoculation of SFTSV newborn Wistar rats, KM, BALB/c, and C57BL/6 mice develop a severe, uniformly lethal disease (Table 3) [73]. The i.p. route of infection decreases the case fatality within susceptible rodents from $100 \%$ to $35-50 \%$. SFTS-like disease in newborn KM mice lasts between 7-17 days, depending on the inoculation dose, and is characterized by decrease in body weight and mobility, piloerection and paralysis of the hind limbs. Aside from overt signs of disease newborn KM mice develop necrosis and mononuclear cell infiltration in liver and brains but not in other tissues [73].

Table 3. Comparison of disease signs between humans and mice following severe fever with thrombocytopenia syndrome virus infection.

\begin{tabular}{|c|c|c|c|c|}
\hline Species & Human & Mouse & & Suckling Mouse \\
\hline & & Untreated & $\begin{array}{l}\text { Mitomycin } \\
\mathrm{C} \text { treated }\end{array}$ & \\
\hline Incubation period & $\leq 21$ days & $\leq 3$ days & Not reported & $6-9$ days \\
\hline Disease duration & 3-7 days & $\leq 18$ days & $\leq 21$ days & $2-8$ days \\
\hline Biphasic & No & No & No & No \\
\hline Disease signs & $\begin{array}{l}\text { Fever, cephalalgia, myalgia, } \\
\text { arthralgia, dizziness, malaise, } \\
\text { mucosal hemorrhage, hemorrhagic } \\
\text { rash, multi-organ failure, } \\
\text { disseminated intravascular } \\
\text { coagulopathy, neurological symptoms }\end{array}$ & None & Weight Loss & $\begin{array}{l}\text { Weight loss, } \\
\text { piloerection, lethargy } \\
\text { and hind limb } \\
\text { paralysis }\end{array}$ \\
\hline $\begin{array}{l}\text { Hematologic } \\
\text { changes }\end{array}$ & $\begin{array}{l}\text { Leukocytopenia, thrombocytopenia, } \\
\text { elevated liver enzymes }\end{array}$ & $\begin{array}{l}\text { Leukocytopenia, } \\
\text { thrombocytopenia, } \\
\text { elevated liver } \\
\text { enzymes }\end{array}$ & Unknown & $\begin{array}{l}\text { Elevated total } \\
\text { bilirubin, decrease in } \\
\text { albumin }\end{array}$ \\
\hline Pathologic changes & Unknown & Liver, spleen & Unknown & Liver \\
\hline Case fatality & $12 \%$ & $0 \%$ & $50 \%$ & $35-100 \%$ \\
\hline
\end{tabular}

A non-lethal C57BL/6 mouse model recapitulates some hematological signs of human SFTS (Table 3) [74]. C57BL/6 mice are susceptible to intravenous (i.v.), i.c., i.p., and intramuscular (i.m.) routes of infection by SFTSV and develop a mild, self-limiting disease. This disease is characterized by an acute ( $<7$ days) viremia accompanied by virus replication in kidney and spleen, transient thrombocytopenia, leukocytopenia, and elevated AST. Following decreased viral loads, increases in blood urea nitrogen (BUN) and ALT are observed followed by appearance of transient liver necrosis and impaired renal capsules accompanied by an increase in SFTSV specific cellular and humoral (neutralizing and total $\mathrm{IgG}$ ) responses. Inhibition of mouse adaptive immune responses with 
mitomycin $\mathrm{C}$, to mimic immune-suppression in humans, results in a more serious disease during which mice lose weight and have a case fatality rate of 50\% [74].

Together the rodent data suggest that impairments in the immune system are required for development of severe disease as has been suggested to occur in severe human SFTS [74]. Based on available data rodent models would be useful as in vivo screening models for antivirals and vaccines; however, due to the limited work reported, whether these animal models faithfully reproduce human disease remains an open question.

\subsection{Severe Fever with Thrombocytopenia Syndrome Virus Summary}

SFTS represents a novel viral hemorrhagic fever, which is currently geographically restricted to North-East China and South-West Japan but threatens a large population. However, lack of information on transmission, disease and endemicity, coupled with the potential of person-to-person transmission may allow SFTSV to spread and cause outbreaks even in distant geographic areas e.g. travel. Therefore, the development of effective postexposure treatments is imperative. To this end, existing rodent animal models of SFTS may be useful as screening models for vaccine development and testing of antivirals. However, rodent models do not mimic human disease progression or case fatality and therefore development of alternate animal models, ideally NHP models, would be desirable for further elucidation of SFTSV pathogenesis.

\section{Crimean-Congo Hemorrhagic Fever Virus}

\subsection{Epidemiology}

In the 1940s, soldiers in Crimea experienced a febrile illness accompanied by severe hemorrhagic manifestations [75-78]. In the 1950s, another febrile illness accompanied by hemorrhagic manifestations was detected in the Belgian Congo (currently Democratic Republic of Congo). In the late 1960 the etiologic agents of the two illnesses were found to be serologically related [79-81] and following further analysis the two were found to be different strains of the same virus. Ultimately, the disease was named Crimean-Congo hemorrhagic fever (CCHF) and the etiologic agent CCHF virus (CCFHV).

In contrast to other TBHFVs, CCHFV is widely distributed and has been reported in over 30 countries spanning Africa, South-Eastern Europe, the Middle East and Western Asia (Figure 1a) [75-78,82]. The incidence of disease is associated with the distribution and activity of its vectors, Hyalomma genus ticks, and transmission of CCHFV to mammals has been demonstrated for several Hyalomma members (Figure 1b) [14,83-87]. The predominant vector of CCHFV varies geographically and include $H$. anatolicum subspecies (especially $H$ anatolicum anatolicum) which are distributed throughout Eurasia and the northern half of Africa; $H$. marginatum subspecies (H. marginatum marginatum, $H$. marginatum rufipes, $H$. marginatum turanicum and $H$. marginatum isaaci) which are distributed throughout Eurasia and Africa; H. truncatum, H. impeltatum, and $H$. impressum which are distributed primarily within Africa[88]. Since its discovery, hundreds of $\mathrm{CCHF}$ cases were reported annually; however, recent outbreaks of CCHF have become more frequent with thousands of case reports annually and the endemic area has expanded to include additional countries within Eurasia. 
CCHFV has a wide host range and can cause a transient viremia in many wild, domesticated and laboratory mammals $[75,76,78,89,90]$, but infection is refractory in most birds [84,91]. CCHFV is transmitted to humans by bite of an infected tick, crushing an engorged infected tick, or by contact with body fluids of viremic humans or animals, suggesting CCHFV is capable of infecting humans via multiple routes of infection.

\subsection{Clinical Presentation}

Following the incubation period, typically 1 to 7 days post exposure, patients experience a rapid onset of high grade fever, fatigue, cephalalgia, dizziness, photophobia and myalgia, often with nausea, vomiting and diarrhea (Table 4) [75,76,78]. Hemorrhagic manifestations develop in severe cases, typically lasting two to three days and are characterized by thrombocytopenia, increases in liver enzymes, petechiae, ecchymosis, epistaxis, gingival hemorrhage, often accompanied by GI and cerebral hemorrhages. Convalescence typically starts 10 to 12 days post symptom onset. The case fatality is variable and ranges from approximately 5\% in Turkey [92], to 60\% in the 1994-1995 CCHF outbreak in the United Arab Emirates [93-95], but is more often reported to be approximately $30 \%$ [75,76,78]. Predictors of fatal outcome in human CCHF are high viral loads, increased serum AST and ALT, severe thrombocytopenia, increased clotting times, increased serum levels pro-inflammatory cytokines and chemokines, low antibody titers and presence of melena [96-108]. Severe liver pathology, DIC, shock and multiorgan failure are the main causes of death $[75,76,78,109]$.

Table 4. Comparison of disease signs between humans and mice following Crimean-Congo hemorrhagic fever virus infection.

\begin{tabular}{|c|c|c|c|c|}
\hline Species & Human & Newborn mice & IFNAR $^{-1-}$ mice & STAT1 $^{-1-}$ mice \\
\hline Incubation period & 1-7 days & $\leq 3$ days & $\leq 3$ days & $\leq 2$ days \\
\hline Disease duration & 10-12 days (average) & 4-5 days & 2-3 days & 1-2 days \\
\hline Biphasic & No & No & No & No \\
\hline Disease signs & $\begin{array}{l}\text { Fever, cephalalgia, myalgia, } \\
\text { arthralgia, dizziness, malaise, mucosal } \\
\text { hemorrhage, hemorrhagic rash, multi- } \\
\text { organ failure, disseminated } \\
\text { intravascular coagulopathy }\end{array}$ & $\begin{array}{l}\text { Weight loss, } \\
\text { piloerection, lethargy, } \\
\text { hind limb paralysis }\end{array}$ & $\begin{array}{l}\text { Weight loss, } \\
\text { piloerection, lethargy, } \\
\text { occasional hemorrhage }\end{array}$ & $\begin{array}{l}\text { Weight loss, } \\
\text { piloerection, lethargy, } \\
\text { occasional hemorrhage }\end{array}$ \\
\hline $\begin{array}{l}\text { Hematologic } \\
\text { changes }\end{array}$ & $\begin{array}{l}\text { Leukocytopenia, thrombocytopenia, } \\
\text { increase clotting times, } \\
\text { increased pro-inflammatory } \\
\text { cytokines/chemokines, } \\
\text { elevated liver enzymes }\end{array}$ & Unknown & $\begin{array}{l}\text { Thrombocytopenia, } \\
\text { increased clotting times, } \\
\text { elevated liver enzymes, } \\
\text { increased } \\
\text { pro-inflammatory } \\
\text { cytokines/chemokines }\end{array}$ & $\begin{array}{l}\text { Thrombocytopenia, } \\
\text { elevated liver enzymes, } \\
\text { increased } \\
\text { pro-inflammatory } \\
\text { cytokines/chemokines }\end{array}$ \\
\hline $\begin{array}{l}\text { Pathologic } \\
\text { changes }\end{array}$ & Liver, spleen, lung & & $\begin{array}{l}\text { Liver, spleen, lymph } \\
\text { node }\end{array}$ & Liver, spleen \\
\hline Case fatality & $3-60 \%$ & $100 \%$ & $100 \%$ & $100 \%$ \\
\hline
\end{tabular}

\subsection{Animal Models of Crimean-Congo Hemorrhagic Fever}

Adult mice, rats, hamsters, guinea pigs, rabbits, ostriches, cattle, sheep, goats, donkeys, horses, and NHPs are susceptible to CCHFV infection but do not develop signs of disease [91,110-112]. 
Newborn mice and rats are susceptible to infection by the i.p. and i.c. routes and exhibit a uniformly fatal disease with neurological signs, which are uncommon in human cases (Table 4) [110]. Newborn mice exhibit weight loss, and paralysis accompanied by viremia and high viral organ titers with an average time to lethal disease of eight days p.i. [110,113]. The only adult animal models available for CCHFV are mouse strains deficient in type I Interferon signaling [114-116].

Signal transduction and activator of signaling-1 knockout $\left(\mathrm{STAT}^{-/}\right)$and Interferon $\alpha \beta$ receptor knockout (IFNAR ${ }^{-1}$ ) mice are susceptible to lethal disease following CCHFV infection [114-116]. Following infection, both STAT1 ${ }^{-/-}$and $\mathrm{IFNAR}^{-/}$mice exhibit a rapid (4-6 days), uniformly lethal disease which mimics several aspects of severe human disease. Both mouse strains exhibit piloerection, lethargy, hunched posture and weight loss accompanied by hemorrhagic manifestations [114-116]. In addition, both mouse strains develop thrombocytopenia and liver dysfunction. Virus is detected in all tissues accompanied by viremia. Pathological changes include severe necrosis and mononuclear cell infiltration of the liver, and lymphocytolysis and necrosis in spleen and lymph nodes. Pathological changes are associated with high levels of viral antigen. Virus infection causes increases in pro-inflammatory chemokines and cytokines suggesting inflammatory responses contribute to disease progression. Therefore, the STAT1 ${ }^{-/}$and IFNAR ${ }^{--}$mouse CCHF models mimic several aspects of severe human disease (Table 4) [114-116]. However, these mice do not recapitulate human disease progression and are therefore likely going to be most useful as screening models for CCHFV countermeasures.

\subsection{Crimean-Congo Hemorrhagic Fever virus Summary}

CCHFV is the most widely distributed TBHFV with an endemic area of $>30$ countries. CCHFV infects a wide range of mammalian hosts but only causes disease in humans, newborn mice and mice strains deficient in type I interferon signaling. While knockout mouse strains offer a tool to assess CCHFV countermeasures, disease progression in these animals differs from human CCHF, which limits the use of the models to study CCHF disease progression. Therefore, the development of animal models, ideally NHP models, which more faithfully reproduce human clinical manifestations are needed to assess disease progression and to confirm efficacy of CCHFV countermeasures in vivo.

\section{Conclusions}

TBHFV are present throughout the Eurasian and African continents and are an emerging or re-emerging threat to many nations. To date, with the exception of CCHFV, TBHFV are geographically limited and not well studied. As a result, limited research tools, most notably animal models, are available for most of these pathogens. In the past decade, however, TBHFVs have emerged (i.e., SFTSV) and areas of endemicity have expanded (i.e., CCHFV and KFDV). Therefore, it is critical to develop new and refine existing animal models for TBHFVs, which mimic human disease, ideally NHPs, to be prepared for further escalation in disease burden. NHP models are preferred as national regulatory authorities, such as the US Food and Drug Administration, consider NHP models the gold standard for efficacy testing of drugs and vaccines for pathogens that would be unethical or unfeasible to be tested in humans [117]. Development of countermeasures is of utmost importance in combating tick-borne viruses as elimination of vectors and interrupting enzootic cycles is all but impossible and ecologically questionable. As in vivo models are the only way to test efficacy and 
safety of countermeasures, development and refinement of animal models is critical in negating the increasing detrimental impact of TBHFVs on public and animal health.

\section{Acknowledgements}

This work was supported by the Division of Intramural Research (DIR), National Institute of Allergy and Infectious Diseases (NIAID), National Institutes of Health (NIH). We would like to thank Tom Schwan (DIR/NIAID/NIH) and Martha Thayer for their assistance in obtaining tick distribution data. We thank Anita Mora, Heather Murphy and Austin Athman (DIR, NIAID, NIH) for their help with the graphical illustrations.

\section{Conflict of Interest}

The authors declare no conflict of interest.

\section{References}

1. Kilpatrick, A.M.; Randolph, S.E. Drivers, dynamics, and control of emerging vector-borne zoonotic diseases. Lancet 2012, 380, 1946-1955.

2. Suss, J. Tick-borne encephalitis 2010: epidemiology, risk areas, and virus strains in Europe and Asia-an overview. Ticks Tick Borne Dis. 2011, 2, 2-15.

3. Mansfield, K.L.; Johnson, N.; Phipps, L.P.; Stephenson, J.R.; Fooks, A.R.; Solomon, T. Tickborne encephalitis virus - a review of an emerging zoonosis. J. Gen. Virol. 2009, 90, 1781-1794.

4. Ruzek, D.; Dobler, G.; Donoso Mantke, O. Tick-borne encephalitis: pathogenesis and clinical implications. Travel Med. Infect. Dis. 2010, 8, 223-232.

5. Dorrbecker, B.; Dobler, G.; Spiegel, M.; Hufert, F.T. Tick-borne encephalitis virus and the immune response of the mammalian host. Travel Med. Infect. Dis. 2010, 8, 213-222.

6. Turtle, L.; Griffiths, M.J.; Solomon, T. Encephalitis caused by flaviviruses. QJM 2012, 105, 219-223.

7. Sips, G.J.; Wilschut, J.; Smit, J.M. Neuroinvasive flavivirus infections. Rev. Med. Virol. 2012, 22, 69-87.

8. Ternovoi, V.A.; Kurzhukov, G.P.; Sokolov, Y.V.; Ivanov, G.Y.; Ivanisenko, V.A.; Loktev, A.V.; Ryder, R.W.; Netesov, S.V.; Loktev, V.B. Tick-borne encephalitis with hemorrhagic syndrome, Novosibirsk region, Russia, 1999. Emerg. Infect. Dis. 2003, 9, 743-746.

9. Ruzek, D.; Yakimenko, V.V.; Karan, L.S.; Tkachev, S.E. Omsk haemorrhagic fever. Lancet 2010, 376, 2104-2113.

10. Pattnaik, P. Kyasanur forest disease: an epidemiological view in India. Rev. Med. Virol. 2006, 16, 151-165.

11. Sun, Y.; Jin, C.; Zhan, F.; Wang, X.; Liang, M.; Zhang, Q.; Ding, S.; Guan, X.; Huo, X.; Li, C.; et al. Host cytokine storm is associated with disease severity of severe fever with thrombocytopenia syndrome. J. Infect. Dis. 2012, 206, 1085-1094.

12. Gai, Z.T.; Zhang, Y.; Liang, M.F.; Jin, C.; Zhang, S.; Zhu, C.B.; Li, C.; Li, X.Y.; Zhang, Q.F.; Bian, P.F.; et al. Clinical progress and risk factors for death in severe fever with thrombocytopenia syndrome patients. J. Infect. Dis. 2012, 206, 1095-1102. 
13. Casals, J.; Henderson, B.E.; Hoogstraal, H.; Johnson, K.M.; Shelokov, A. A review of Soviet viral hemorrhagic fevers, 1969. J. Infect. Dis. 1970, 122, 437-453.

14. Kolonin, G.V. Fauna of Ixodid Ticks of the World (Acari, Ixodidae). 2009. Available online at: http://www.kolonin.org/1.html (access on 22 May 2013).

15. Holbrook, M.R.; Aronson, J.F.; Campbell, G.A.; Jones, S.; Feldmann, H.; Barrett, A.D. An animal model for the tickborne flavivirus--Omsk hemorrhagic fever virus. J. Infect. Dis. 2005, 191, 100-108.

16. Kenyon, R.H.; Rippy, M.K.; McKee, K.T., Jr.; Zack, P.M.; Peters, C.J. Infection of Macaca radiata with viruses of the tick-borne encephalitis group. Microb. Pathog. 1992, 13, 399-409.

17. Tigabu, B.; Juelich, T.; Holbrook, M.R. Comparative analysis of immune responses to Russian spring-summer encephalitis and Omsk hemorrhagic fever viruses in mouse models. Virology 2010, 408, 57-63.

18. Tigabu, B.; Juelich, T.; Bertrand, J.; Holbrook, M.R. Clinical evaluation of highly pathogenic tick-borne flavivirus infection in the mouse model. J. Med. Virol. 2009, 81, 1261-1269.

19. Shestopalova, N.M.; Reingold, V.N.; Gagarina, A.V.; Kornilova, E.A.; Popov, G.V.; Chumakov, M.P. Electron microscopic study of the central nervous system in mice infected by Omsk hemorrhagic fever (OHF) virus. Virus reproduction in cerebellum neurons. J. Ultrastruct. Res. 1972, 40, 458-469.

20. Pripuzova, N.S.; Gmyl, L.V.; Romanova, L.; Tereshkina, N.V.; Rogova, Y.V.; Terekhina, L.L.; Kozlovskaya, L.I.; Vorovitch, M.F.; Grishina, K.G.; Timofeev, A.V.; et al. Exploring of primate models of tick-borne flaviviruses infection for evaluation of vaccines and drugs efficacy. PLoS One 2013, 8, e61094.

21. Work, T.H.; Trapido, H. Kyasanur Forest Disease A New Virus Disease in India. Indian J. Med. Sci. 1957, 11, 341-345.

22. Iyer, C.G.S.; Work, T.H.; Narasimha Murthy, D.P.; Trapido, H.; Rajagopalan, P.K. Pathological Findings in Monkeys, Presbytis entellus and Macaca radiata, Found Dead in the Forest. Indian J. Med. Res. 1960, 48, 276-286.

23. Pavri, K. Clinical, clinicopathologic, and hematologic features of Kyasanur Forest disease. Rev. Infect. Dis. 1989, 11(Suppl 4), S854-S859.

24. Verma, M.G.; Webb, H.E.; Pavri, K. Studies on the transmission of Kyasanur Forest disease virus by Haemaphysalis spinigera Newman. Transfusion (Paris) 1960, 54, 509-516.

25. Trapido, H.; Rajagopalan, P.K.; Work, T.H.; Varma, M.G.R. Isolation of Kyasanur Forest Disease Virus From Naturally Infected Ticks of the Genus Haemaphysalis. Indian J. Med. Res. 1959, 47, 133-138.

26. Singh, K.R.; Pavri, K.; Anderson, C.R. Experimental Transovarial Transmission of Kyasanur Forest Disease Virus in Haemaphysalis Spinigera. Nature 1963, 199, 513.

27. Singh, K.R.; Pavri, K.; Anderson, C.R. Transmission of Kyasanur forest disease by Haemaphysalis tururis, Haemaphysalis papuana kinneari and Haemaphysalis minuta. Indian J. Med. Res. 1964, 52, 566-573.

28. Bhat, H.R.; Sreenivasan, M.K.; Goverdhan, M.K.; Naik, S.V. Transmission of Kyasanur Forest Disease Virus by Haemaphysalis Kyasanurensis Trapido, Hoogstraal and Rajagopalan, 1964 (Acarina : Ixodidae). Indian J. Med. Res. 1975, 63, 879-887. 
29. Singh, K.R.; Bhatt, P.N. Transmission of Kyasanur Forest disease virus by Hyalomma marginatum isaaci. Indian J. Med. Res. 1968, 56, 610-613.

30. Singh, K.R.; Goverdhan, M.K.; Rao, T.R. Experimental transmission of Kyasanur forest disease virus to small mammals by Ixodes petauristae, I. ceylonensis and Haemaphysalis spinigera. Indian J. Med. Res. 1968, 56, 594-609.

31. Singh, K.R.; Goverdhan, M.K.; Bhat, U.K. Transmission of Kyasanur Forest disease virus by soft tick, Argas persicus (Ixodoidea: Argasidae). Indian J. Med. Res. 1971, 59, 213-218.

32. Bhat, U.K.; Goverdhan, M.K. Transmission of Kyasanur Forest disease virus by the soft tick, Ornithodoros crossi. Acta Virol. 1973, 17, 337-342.

33. Boshell, J.; Rajagopalan, P.K. Preliminary studies on experimental transmission of Kyasanur Forest disease virus by nymphs of Ixodes petauristae Warburton, 1933, infected as larvae on Suncus murinus and Rattus blanfordi. Indian J. Med. Res. 1968, 56, 589-593.

34. Boshell, J.; Rajagopalan, P.K.; Patil, A.P.; Pavri, K.M. Isolation of Kyasanur Forest disease virus from ixodid ticks: 1961-1964. Indian J. Med. Res. 1968, 56, 541-568.

35. Boshell, J. Kyasanur Forest disease: ecologic considerations. Am. J. Trop. Med. Hyg. 1969, 18, 67-80.

36. Wang, J.; Zhang, H.; Fu, S.; Wang, H.; Ni, D.; Nasci, R.; Tang, Q.; Liang, G. Isolation of kyasanur forest disease virus from febrile patient, yunnan, china. Emerg. Infect. Dis. 2009, 15, 326-328.

37. Mehla, R.; Kumar, S.R.; Yadav, P.; Barde, P.V.; Yergolkar, P.N.; Erickson, B.R.; Carroll, S.A.; Mishra, A.C.; Nichol, S.T.; Mourya, D.T. Recent ancestry of Kyasanur Forest disease virus. Emerg. Infect. Dis. 2009, 15, 1431-1437.

38. Madani, T.A. Alkhumra virus infection, a new viral hemorrhagic fever in Saudi Arabia. J. Infect. 2005, 51, 91-97.

39. Zaki, A.M. Isolation of a flavivirus related to the tick-borne encephalitis complex from human cases in Saudi Arabia. Trans. R. Soc. Trop. Med. Hyg. 1997, 91, 179-181.

40. Charrel, R.N.; Gould, E.A. Alkhurma hemorrhagic fever in travelers returning from Egypt, 2010. Emerg. Infect. Dis. 2011, 17, 1573-1574; author reply 1574.

41. Madani, T.A.; Kao, M.; Azhar, E.I.; Abuelzein el, T.M.; Al-Bar, H.M.; Abu-Araki, H.; Ksiazek, T.G. Successful propagation of Alkhumra (misnamed as Alkhurma) virus in C6/36 mosquito cells. Trans. R. Soc. Trop. Med. Hyg. 2012, 106, 180-185.

42. Madani, T.A.; Azhar, E.I.; Abuelzein el, T.M.; Kao, M.; Al-Bar, H.M.; Abu-Araki, H.; Niedrig, M.; Ksiazek, T.G. Alkhumra (Alkhurma) virus outbreak in Najran, Saudi Arabia: epidemiological, clinical, and laboratory characteristics. J. Infect. 2011, 62, 67-76.

43. Dodd, K.A.; Bird, B.H.; Khristova, M.L.; Albarino, C.G.; Carroll, S.A.; Comer, J.A.; Erickson, B.R.; Rollin, P.E.; Nichol, S.T. Ancient ancestry of KFDV and AHFV revealed by complete genome analyses of viruses isolated from ticks and mammalian hosts. PLoS Negl. Trop. Dis. 2011, 5, e1352.

44. International Committee on Taxonomy of Viruses. January 2013. Available online at: http://www.ictvonline.org/virusTaxonomy.asp?bhcp=1 (access on 22 May 2013). 
45. Memish, Z.A.; Fagbo, S.F.; Assiri, A.M.; Rollin, P.; Zaki, A.M.; Charrel, R.; Mores, C.; MacNeil, A. Alkhurma viral hemorrhagic fever virus: proposed guidelines for detection, prevention, and control in Saudi Arabia. PLoS Negl. Trop. Dis. 2012, 6, e1604.

46. Bhat, H.R.; Sreenivasan, M.A.; Goverdhan, M.K.; Naik, S.V.; Banerjee, K. Susceptibility of Hystrix indica Kerr, 1792, Indian crested porcupine (Rodentia Hystricidae) to KFD virus. Indian J. Med. Res. 1976, 64, 1566-1570.

47. Sreenivasan, M.A.; Bhat, H.R. Susceptibility of Vandeleuria oleracea Bennet, 1832 (Rodentia, Muridae) to experimental infection with Kyasanur forest disease virus. Indian J. Med. Res. 1976, 64, 568-572.

48. Goverdhan, M.K.; Anderson, C.R. The reaction of Mus platythrix to Kyasanur Forest Disease Virus. Indian J. Med. Res. 1972, 60, 1002-1006.

49. Sreenivasan, M.A.; Bhat, H.R. Susceptibility of Lepus nigricollis Cuvier, to experimental infection with Kyasanur Forest Disease virus. Indian J. Med. Res. 1977, 65, 17-20.

50. Goverdhan, M.K.; Anderson, C.R. The reaction of Funambulus tristriatus tristriatus Rattus blanfordi and Suncus murinus to Kyasanur forest disease virus. Indian J. Med. Res. 1981, 74, 141-146.

51. Anderson, C.R.; Singh, K.R. The reaction of cattle to Kyasanur Forest disease virus. Indian J. Med. Res. 1971, 59, 195-198.

52. Webb, H.E. Kyasanur Forest Disease Virus in Three Species on Rodents. Trans. R. Soc. Trop. Med. Hyg. 1965, 59, 205-211.

53. Goverdhan, M.K.; Rajagopalan, P.K.; Narasimha Murthy, D.P.; Upadhyaya, S.; Boshell, M.J.; Trapido, H.; Ramachandra Rao, T. Epizootiology of Kyasanur Forest Disease in wild monkeys of Shimoga district, Mysore State (1957-1964). Indian J. Med. Res. 1974, 62, 497-510.

54. Webb, H.E.; Burston, J. Clinical and pathological observations with special reference to the nervous system in Macaca radiata infected with Kyasanur Forest Disease virus. Trans. R. Soc. Trop. Med. Hyg. 1966, 60, 325-331.

55. Work, T.H. Russian Spring-Summer Virus in India - Kyasanur Forest Disease. Prog. Med. Virol. 1958, 1, 248-279.

56. Nayar, M. Kyasanur Forest disease virus encephalitis in mice. Effect of cortisone on the encephalitic lesions. Indian J. Med. Res. 1972, 60, 1427-1431.

57. Nayar, M. Histological changes in mice infected with Kyasanur Forest disease virus. Indian J. Med. Res. 1972, 60, 1421-1426.

58. Price, W.H. Chronic Disease and Virus Persistence in Mice Inoculated with Kyasanur Forest Disease Virus. Virology 1966, 29, 679-681.

59. Mansharamani, H.J.; Dandawate, C.N. Experimental vaccine against Kyasanur Forest disease (KFD) virus from tissue culture source. II. Safety testing of the vaccine in cortisone sensitized Swiss albino mice. Indian J. Pathol. Bacteriol. 1967, 10, 25-32.

60. Mansharamani, H.J.; Dandawate, C.N.; Krishnamurthy, B.G. Experimental vaccine against Kyasanur Forest disease (KFD) virus from tissue culture source. I. Some data on the preparation and antigenicity tests of vaccines. Indian J. Pathol. Bacteriol. 1967, 10, 9-24. 
61. Xu, B.; Liu, L.; Huang, X.; Ma, H.; Zhang, Y.; Du, Y.; Wang, P.; Tang, X.; Wang, H.; Kang, K.; et al. Metagenomic Analysis of Fever, Thrombocytopenia and Leukopenia Syndrome (FTLS) in Henan Province, China: Discovery of a New Bunyavirus. PLoS Pathog. 2011, 7, e1002369.

62. Yu, X.-J.; Liang, M.-F.; Zhang, S.-Y.; Liu, Y.; Li, J.-D.; Sun, Y.-L.; Zhang, L.; Zhang, Q.-F.; Popov, V.L.; Li, C.; et al. Fever with Thrombocytopenia Associated with a Novel Bunyavirus in China. New Eng. J. Med. 2011, 364, 1523-1532.

63. Zhang, Y.Z.; Zhou, D.J.; Xiong, Y.; Chen, X.P.; He, Y.W.; Sun, Q.; Yu, B.; Li, J.; Dai, Y.A.; Tian, J.H.; et al. Hemorrhagic fever caused by a novel tick-borne Bunyavirus in Huaiyangshan, China. Zhonghua Liu Xing Bing Xue Za Zhi 2011, 32, 209-220.

64. Ministry of Health, Labor and Welfare, report on SFTSV. 11 February 2013. Available online at: http://www.mhlw.go.jp/stf/houdou/2r9852000002u1pm.html (access on 22 May 2013).

65. ProMED Severe Fever With Thrombocytopenia Syndrome - Japan: (Ehime) Fatalities. 14 Feb. 2013. Available online at: http://www.promedmail.org/direct.php?id=20130214.1542725 (access on 22 May 2013).

66. Chen, H.; Hu, K.; Zou, J.; Xiao, J. A cluster of cases of human-to-human transmission caused by severe fever with thrombocytopenia syndrome bunyavirus. Int. J. Infect. Dis. 2012, 17, e206-e208.

67. Bao, C.J.; Guo, X.L.; Qi, X.; Hu, J.L.; Zhou, M.H.; Varma, J.K.; Cui, L.B.; Yang, H.T.; Jiao, Y.J.; Klena, J.D.; et al. A Family Cluster of Infections by a Newly Recognized Bunyavirus in Eastern China, 2007: Further Evidence of Person-to-Person Transmission. Clin. Infect. Dis. 2011, $53,1208-1214$.

68. Liu, Y.; Li, Q.; Hu, W.; Wu, J.; Wang, Y.; Mei, L.; Walker, D.H.; Ren, J.; Yu, X.J. Person-toperson transmission of severe fever with thrombocytopenia syndrome virus. Vector Borne Zoonotic Dis. 2012, 12, 156-160.

69. Gai, Z.; Liang, M.; Zhang, Y.; Zhang, S.; Jin, C.; Wang, S.W.; Sun, L.; Zhou, N.; Zhang, Q.; Sun, Y.; et al. Person-to-person transmission of severe fever with thrombocytopenia syndrome bunyavirus through blood contact. Clin. Infect. Dis. 2012, 54, 249-252.

70. Zhang, L.; Wang, X.; Zhang, Y.; Wang, H.; Wang, C.; Sun, J.; Lin, J.; Chai, C.; Yan, J. Severe fever with thrombocytopenia syndrome bunyavirus (SFTSV) infections in Zhejiang Province, China. Int. J. Infect. Dis. 2012, 17, e137-e138.

71. Liu, L.; Guan, X.H.; Xing, X.S.; Shen, X.F.; Xu, J.Q.; Yue, J.L.; Huo, X.X.; Sha, S.; Wu, H.X.; Huang, J.; et al. Epidemiologic analysis on severe fever with thrombocytopenia syndrome in Hubei province, 2010. Zhonghua Liu Xing Bing Xue Za Zhi 2012, 33, 168-172.

72. Jiao, Y.; Zeng, X.; Guo, X.; Qi, X.; Zhang, X.; Shi, Z.; Zhou, M.; Bao, C.; Zhang, W.; Xu, Y.; et al. Preparation and evaluation of recombinant severe fever with thrombocytopenia syndrome virus nucleocapsid protein for detection of total antibodies in human and animal sera by doubleantigen sandwich enzyme-linked immunosorbent assay. J. Clin. Microbiol. 2012, 50, 372-377.

73. Chen, X.P.; Cong, M.L.; Li, M.H.; Kang, Y.J.; Feng, Y.M.; Plyusnin, A.; Xu, J.; Zhang, Y.Z. Infection and pathogenesis of Huaiyangshan virus (a novel tick-borne bunyavirus) in laboratory rodents. J. Gen. Virol. 2012, 93, 1288-1293.

74. Jin, C.; Liang, M.; Ning, J.; Gu, W.; Jiang, H.; Wu, W.; Zhang, F.; Li, C.; Zhang, Q.; Zhu, H.; et al. Pathogenesis of emerging severe fever with thrombocytopenia syndrome virus in C57/BL6 mouse model. Proc. Natl. Acad. Sci. USA 2012, 109, 10053-10058. 
75. Ergonul, O. Crimean-Congo haemorrhagic fever. Lancet Infect. Dis. 2006, 6, 203-214.

76. Whitehouse, C.A. Crimean-Congo hemorrhagic fever. Antiviral Res. 2004, 64, 145-160.

77. Flick, R.; Whitehouse, C.A. Crimean-Congo hemorrhagic fever virus. Curr. Mol. Med. 2005, 5, 753-760.

78. Vorou, R.; Pierroutsakos, I.N.; Maltezou, H.C. Crimean-Congo hemorrhagic fever. Curr. Opin. Infect. Dis. 2007, 20, 495-500.

79. Chumakov, M.P.; Smirnova, S.E.; Tkachenko, E.A. Relationship between strains of Crimean haemorrhagic fever and Congo viruses. Acta Virol. 1970, 14, 82-85.

80. Casals, J. Antigenic similarity between the virus causing Crimean hemorrhagic fever and Congo virus. Proc. Soc. Exp. Biol. Med. 1969, 131, 233-236.

81. Casals, J.; Tignor, G.H. Neutralization and hemagglutination-inhibition tests with Crimean hemorrhagic fever-Congo virus. Proc. Soc. Exp. Biol. Med. 1974, 145, 960-966.

82. Ergonul, O. Crimean-Congo hemorrhagic fever virus: new outbreaks, new discoveries. Curr. Opin. Virol. 2012, 2, 215-220.

83. Gordon, S.W.; Linthicum, K.J.; Moulton, J.R. Transmission of Crimean-Congo hemorrhagic fever virus in two species of Hyalomma ticks from infected adults to cofeeding immature forms. Am. J. Trop. Med. Hyg. 1993, 48, 576-580.

84. Zeller, H.G.; Cornet, J.P.; Camicas, J.L. Experimental transmission of Crimean-Congo hemorrhagic fever virus by west African wild ground-feeding birds to Hyalomma marginatum rufipes ticks. Am. J. Trop. Med. Hyg. 1994, 50, 676-681.

85. Logan, T.M.; Linthicum, K.J.; Bailey, C.L.; Watts, D.M.; Moulton, J.R. Experimental transmission of Crimean-Congo hemorrhagic fever virus by Hyalomma truncatum Koch. Am. J. Trop. Med. Hyg. 1989, 40, 207-212.

86. Dohm, D.J.; Logan, T.M.; Linthicum, K.J.; Rossi, C.A.; Turell, M.J. Transmission of CrimeanCongo hemorrhagic fever virus by Hyalomma impeltatum (Acari:Ixodidae) after experimental infection. J. Med. Entomol. 1996, 33, 848-851.

87. Shepherd, A.J.; Swanepoel, R.; Cornel, A.J.; Mathee, O. Experimental studies on the replication and transmission of Crimean-Congo hemorrhagic fever virus in some African tick species. Am. J. Trop. Med. Hyg. 1989, 40, 326-331.

88. Hoogstraal, H. The epidemiology of tick-borne Crimean-Congo hemorrhagic fever in Asia, Europe, and Africa. J. Med. Entomol. 1979, 15, 307-417.

89. Shepherd, A.J.; Leman, P.A.; Swanepoel, R. Viremia and antibody response of small African and laboratory animals to Crimean-Congo hemorrhagic fever virus infection. Am. J. Trop. Med. Hyg. 1989, 40, 541-547.

90. Shepherd, A.J.; Swanepoel, R.; Shepherd, S.P.; McGillivray, G.M.; Searle, L.A. Antibody to Crimean-Congo hemorrhagic fever virus in wild mammals from southern Africa. Am. J. Trop. Med. Hyg. 1987, 36, 133-142.

91. Swanepoel, R.; Leman, P.A.; Burt, F.J.; Jardine, J.; Verwoerd, D.J.; Capua, I.; Bruckner, G.K.; Burger, W.P. Experimental infection of ostriches with Crimean-Congo haemorrhagic fever virus. Epidemiol. Infect. 1998, 121, 427-432. 
92. Kubar, A.; Haciomeroglu, M.; Ozkul, A.; Bagriacik, U.; Akinci, E.; Sener, K.; Bodur, H. Prompt administration of Crimean-Congo hemorrhagic fever (CCHF) virus hyperimmunoglobulin in patients diagnosed with CCHF and viral load monitorization by reverse transcriptase-PCR. Jpn. J. Infect. Dis. 2011, 64, 439-443.

93. Schwarz, T.F.; Nsanze, H.; Longson, M.; Nitschko, H.; Gilch, S.; Shurie, H.; Ameen, A.; Zahir, A.R.; Acharya, U.G.; Jager, G. Polymerase chain reaction for diagnosis and identification of distinct variants of Crimean-Congo hemorrhagic fever virus in the United Arab Emirates. Am. J. Trop. Med. Hyg. 1996, 55, 190-196.

94. Khan, A.S.; Maupin, G.O.; Rollin, P.E.; Noor, A.M.; Shurie, H.H.; Shalabi, A.G.; Wasef, S.; Haddad, Y.M.; Sadek, R.; Ijaz, K.; et al. An outbreak of Crimean-Congo hemorrhagic fever in the United Arab Emirates, 1994-1995. Am. J. Trop. Med. Hyg. 1997, 57, 519-525.

95. Rodriguez, L.L.; Maupin, G.O.; Ksiazek, T.G.; Rollin, P.E.; Khan, A.S.; Schwarz, T.F.; Lofts, R.S.; Smith, J.F.; Noor, A.M.; Peters, C.J.; et al. Molecular investigation of a multisource outbreak of Crimean-Congo hemorrhagic fever in the United Arab Emirates. Am. J. Trop. Med. Hyg. 1997, 57, 512-518.

96. Cevik, M.A.; Erbay, A.; Bodur, H.; Eren, S.S.; Akinci, E.; Sener, K.; Onguru, P.; Kubar, A. Viral load as a predictor of outcome in Crimean-Congo hemorrhagic fever. Clin. Infect. Dis. 2007, 45, e96-e100.

97. Cevik, M.A.; Erbay, A.; Bodur, H.; Gulderen, E.; Bastug, A.; Kubar, A.; Akinci, E. Clinical and laboratory features of Crimean-Congo hemorrhagic fever: predictors of fatality. Int. J. Infect. Dis. 2008, 12, 374-379.

98. Onguru, P.; Dagdas, S.; Bodur, H.; Yilmaz, M.; Akinci, E.; Eren, S.; Ozet, G. Coagulopathy parameters in patients with Crimean-Congo hemorrhagic fever and its relation with mortality. $J$. Clin. Lab. Anal. 2010, 24, 163-166.

99. Papa, A.; Bino, S.; Velo, E.; Harxhi, A.; Kota, M.; Antoniadis, A. Cytokine levels in CrimeanCongo hemorrhagic fever. J. Clin. Virol. 2006, 36, 272-276.

100. Saksida, A.; Duh, D.; Wraber, B.; Dedushaj, I.; Ahmeti, S.; Avsic-Zupanc, T. Interacting roles of immune mechanisms and viral load in the pathogenesis of crimean-congo hemorrhagic fever. Clin. Vaccine Immunol. 2010, 17, 1086-1093.

101. Weber, F.; Mirazimi, A. Interferon and cytokine responses to Crimean Congo hemorrhagic fever virus; an emerging and neglected viral zonoosis. Cytokine Growth Factor Rev. 2008, 19, 395-404.

102. Yesilyurt, M.; Gul, S.; Ozturk, B.; Kayhan, B.C.; Celik, M.; Uyar, C.; Erdogan, F. The early prediction of fatality in Crimean Congo hemorrhagic fever patients. Saudi Med. J. 2011, 32, 742-743.

103. Yilmaz, G.; Koksal, I.; Topbas, M.; Yilmaz, H.; Aksoy, F. The effectiveness of routine laboratory findings in determining disease severity in patients with Crimean-Congo hemorrhagic fever: severity prediction criteria. J. Clin. Virol. 2010, 47, 361-365.

104. Duh, D.; Saksida, A.; Petrovec, M.; Ahmeti, S.; Dedushaj, I.; Panning, M.; Drosten, C.; AvsicZupanc, T. Viral load as predictor of Crimean-Congo hemorrhagic fever outcome. Emerg. Infect. Dis. 2007, 13, 1769-1772.

105. Ergonul, O.; Celikbas, A.; Baykam, N.; Eren, S.; Dokuzoguz, B. Analysis of risk-factors among patients with Crimean-Congo haemorrhagic fever virus infection: severity criteria revisited. Clin. Microbiol. Infect. 2006, 12, 551-554. 
106. Ergonul, O.; Tuncbilek, S.; Baykam, N.; Celikbas, A.; Dokuzoguz, B. Evaluation of serum levels of interleukin (IL)-6, IL-10, and tumor necrosis factor-alpha in patients with Crimean-Congo hemorrhagic fever. J. Infect. Dis. 2006, 193, 941-944.

107. Papa, A.; Drosten, C.; Bino, S.; Papadimitriou, E.; Panning, M.; Velo, E.; Kota, M.; Harxhi, A.; Antoniadis, A. Viral load and Crimean-Congo hemorrhagic fever. Emerg. Infect. Dis. 2007, 13, 805-806.

108. Wolfel, R.; Paweska, J.T.; Petersen, N.; Grobbelaar, A.A.; Leman, P.A.; Hewson, R.; GeorgesCourbot, M.C.; Papa, A.; Gunther, S.; Drosten, C. Virus detection and monitoring of viral load in Crimean-Congo hemorrhagic fever virus patients. Emerg. Infect. Dis. 2007, 13, 1097-1100.

109. Burt, F.J.; Swanepoel, R.; Shieh, W.J.; Smith, J.F.; Leman, P.A.; Greer, P.W.; Coffield, L.M.; Rollin, P.E.; Ksiazek, T.G.; Peters, C.J.; et al. Immunohistochemical and in situ localization of Crimean-Congo hemorrhagic fever (CCHF) virus in human tissues and implications for CCHF pathogenesis. Arch. Pathol. Lab. Med. 1997, 121, 839-846.

110. Smirnova, S.E. A comparative study of the Crimean hemorrhagic fever-Congo group of viruses. Arch. Virol. 1979, 62, 137-143.

111. Fagbami, A.H.; Tomori, O.; Fabiyi, A.; Isoun, T.T. Experimantal Congo virus (Ib -AN 7620) infection in primates. Virologie 1975, 26, 33-37.

112. Blagoveshchenskaya, N.M.; Butenko, A.M.; Vyshnivetskaya, L.K.; Zavodova, T.I.; Zarubina, L.V.; Karinskaya, G.A.; Kuchin, V.V.; Milyutin, V.N.; Novikova, E.M.; Rubin, S.G.; et al. Experimental infection of horses with Crimean hemorrhagic fever virus. Report 2. Virological and serological observations. Mater. 16 Nauchn. Sess. Inst. Polio Virusn. Entsefalitov. (Moscow, October 1969) 1969, 2, 126-127.

113. Tignor, G.H.; Hanham, C.A. Ribavirin efficacy in an in vivo model of Crimean-Congo hemorrhagic fever virus (CCHF) infection. Antiviral. Res. 1993, 22, 309-325.

114. Bente, D.A.; Alimonti, J.B.; Shieh, W.J.; Camus, G.; Stroher, U.; Zaki, S.; Jones, S.M. Pathogenesis and immune response of Crimean-Congo hemorrhagic fever virus in a STAT-1 knockout mouse model. J. Virol. 2010, 84, 11089-11100.

115. Bereczky, S.; Lindegren, G.; Karlberg, H.; Akerstrom, S.; Klingstrom, J.; Mirazimi, A. CrimeanCongo hemorrhagic fever virus infection is lethal for adult type I interferon receptor-knockout mice. J. Gen. Virol. 2010, 91, 1473-1477.

116. Zivcec, M.; Safronetz, D.; Scott, D.; Robertson, S.; Ebihara, H.; Feldmann, H. Lethal CrimeanCongo Hemorrhagic Fever virus infection in interferon alpha/beta receptor knockout mice is associated with high viral loads, pro-inflammatory responses and coagulopathy. J. Infect. Dis. 2013, doi: 10.1093/infdis/jit061.

117. New drug and biological drug products; evidence needed to demonstrate effectiveness of new drugs when human efficacy studies are not ethical or feasible. Final rule. Fed. Regist. 2002, 67, 37988-37998.

(C) 2013 by the authors; licensee MDPI, Basel, Switzerland. This article is an open access article distributed under the terms and conditions of the Creative Commons Attribution license (http://creativecommons.org/licenses/by/3.0/). 